\title{
Perception of secondary school adolescent girls on their own diet and health status in urban Benin
}

\author{
Sherifath Mama Chabi ${ }^{1 *}$, Nadia Fanou Fogny ${ }^{1}$, Eunice Nago Koukoubou ${ }^{1}$, Axel Egbakotan ${ }^{1}$, and Yrence Amoussou \\ Lokossou ${ }^{1}$ \\ ${ }^{l}$ University of Abomey-Calavi, Benin
}

Abstract. From childhood to adulthood, adolescence phase transition, implies many lifestyle changes. This study aims to investigate the perception of adolescent girls of their own diet and health status. A cross-sectional study, using a structured face-to-face administered questionnaire, were carried out in 395 adolescent girls 15 - 19 years old in secondary schools in Cotonou, in Benin. Chi 2 and Wilcoxon - Mann Whitney tests were performed to appreciate the variables associations. Logistic regression was executed to appraise the effect of self-perception on dietary practices. The average age of the participants was $16.7 \pm 1.26$ years. The prevalence of selfreported anaemia, diet quality and overweight/obesity was $18.23 \% ; 57.72 \%$ and $9.87 \%$ respectively. Considering school character, more adolescents in private schools perceived themselves as being "overweight/obese" $(22.8 \%)$ compared to their peers from public schools $(0.4 \%)$. Self-perceived anaemia was related to dark green leafy vegetable and vitamin C-rich fruits consumption while self-perceived overweight/obesity decrease the consumption of meat and meat products. Adolescents who perceived their own diet as healthy reached the Minimum Dietary Diversity. The findings of this study highlight the importance of self-perception in adolescents eating habits and this should be considered in interventions improving their diet quality.

Key-words: Adolescent girls, self-perception, anaemia, eating habits, overweight, obesity

\section{Introduction}

In life cycle, adolescence is the period between childhood and adulthood where habits are formed and persist into adult life [1]. At this age, adolescents are highly exposed to health issues and malnutrition [2].

In Benin, overweight and anaemia are among the most prevalent nutritional disorders in adolescent girls. The prevalence of anaemia in non-pregnant girls aged 15 - 19 years is $57.4 \%$ [3] and $17.6 \%$ of them in urban areas are overweight with $13 \%$ in rural areas [4]. There is an increasing presence of multiple burdens of malnutrition in urban Africa, in addition to the nutrition transition [5], which made urban adolescents more at risk of malnutrition and health issues. Developing adequate health status from childhood to adulthood, including adolescence, is related to dietary habits with the consumption of adequate nutrients and foods [6]. Unfortunately, adolescents are exposed to unhealthy behaviours (including unhealthy eating behaviours) [7] reducing their probability to cover their nutrients needs at this age period $[8,9]$.

Moreover, different determinants have been related to eating behaviours [10]. Among these, perception is described as an important factor [11]. Perception is defined as an important individual-level concept and psychosocial determinant associated with behaviour and choices [12]. The nature of this association between risk perceptions and health behaviours might be due to the different types of risk perceptions and their accuracy in people's life [11]. Regarding the importance the importance of perception in health promotion behaviour, inadequate perception of diet quality could perpetuate poor dietary habits [12]. Besides, an imperfect selfperception of diet can impede the improvement of diet quality, then preventing individuals who consider their diet as already healthyfrom feeling the need to improve it [13]. Moreover, weight misperception might conduct to eating disorders [14] and self-perceived overweight is related to higher eating disorders in adolescents [15]. The same disconnect was found about the perception of anaemia and it was identified as complex for improving interventions towards anaemia [16].

Therefore, an accurate perception of weight and anaemia as nutritional disorder and health issue is important to access and succeed in education and behaviour intervention programs among adolescents [17]. This study aims to investigate the perception of adolescent girls of their own diet and health status and appreciate the effect on their current diet.

\section{Methodology}

\subsection{Study design}

This study is part of the baseline component of a research project aiming at identifying factors associated with adolescent girls eating behaviours in Urban Benin. It is a cross-sectional study conducted in secondary schools in the city of Cotonou in Benin, with adolescent girls, using a mixed qualitative-semi-quantitative approach for data collection. Ethical clearance for the whole research was obtained from the Local Committee for the biomedical research of Benin.

\subsection{Participants and sampling}

Study participants were adolescent girls from 15 to 19 years of age, of any ethnicity attending secondary schools. A sample size of 350 was estimated sufficient for this descriptive study, for a power test of $80 \%$ and at $95 \%$ Confidence Interval (CI), with a non-response rate of 5\%.

Participants were selected using a stratified sampling method, the first strata being the geographical distribution of the school, the second being the private/public status and the third being the level at secondary school. First, based on a minimum estimate of $10 \%$ coverage of the secondary schools of Cotonou and a minimum number of 25 respondents per school, 17 schools were randomly selected from the total of 142 secondary schools in Cotonou, considering the private/public status and geographical position to maximize variability. In each school, a brief presentation of the study was made to the 
board and consent were obtained from 14 schools. In these schools, information note was sent to all parents of pupil girls aged 15 - 19 years old attending the second cycle of secondary education. Only the second cycle was considered because, among the 4 cycles in the Benin education system (nursery school, primary school, secondary school, and University), the second cycle in secondary schools usually comprises students aged 15 19 years old and attending fifth to seventh grade. The girls who obtained the signed consent from at least one of their parents and willing to participate were enrolled. Thus, a total of 395 girls aged 15 - 19 years old in the second cycle of the secondary school participated in the study.

\subsection{Data collection}

Adolescents' perception of their own diet was measured using the FAO Knowledge, Attitude and Practice questionnaire (KAP) [18]. Girls were asked to appreciate their own diet on 5 scales, from "Very unhealthy" to "Very healthy" coded from 0 to 4 respectively. Participants' self-perception of suffering from iron deficiency anaemia (IDA) and overweight/obesity was appraised respectively with iron-rich food consumption and junk foods intake. Perception of IDA was measured with the question: "How likely do you think you are irondeficient/anaemic?" and Self-perception of being overweight/obesity was determined with one question asking "How overweight or obese do you think you are?" with response option of "Not likely", "I am not sure", or "Likely". The perception of being ID anaemic and overweight/obesity were both coded from 0 to 2 with higher numbers corresponding to "Likely".

The eating habits of participants was assessed using the $24 \mathrm{~h}$ recall questionnaire administered on two nonconsecutive days among adolescent girls [19]. Meat and meat products as well as dark leafy vegetables and Vitamin-C rich fruit (citrus) consumption were categorized as preventing IDA [20]. The diet quality was assessed with the Minimum Dietary Diversity for Women of reproductive age (MDDW) at 5 and above, out of the 10 recommended food groups [21] and the Global Dietary Recommendations (GDR) score at 1 and above [22]. Unhealthy foods consumption was defined as the consumption of at least one Fried and salty foods, sweet foods or sweet beverages the day before the survey [21].

\subsection{Data analysis}

All the analyses were processed using SPSS version 20.0, Chicago, Illinois. MDDW and GDR were computed as the average of the two consecutive days (details to be described in next publication). Descriptive statistics were performed to describe the sample. Chi 2 and Wilcoxon Mann Whitney tests were used for comparison of selfperception between age groups (15 - 17 years and $18-19$ years) and school status (private and public), at a significance level of $5 \%$. To assess the relationship between self-perception and eating habits, a logistic regression model was run, with "anaemia perception", "overweight/obesity perception" and "diet perception" as response variables, using "meat and meat consumption", "dark green leafy vegetable and vitamin C-rich fruits", "GDR score", "MDDW" and "unhealthy foods consumption", "age" and "school status" as factors. For the variables "anaemia perception" and "overweight/obesity perception", modalities "maybe anaemic" for anaemia self-perception and "overweight/obesity" for overweight/obesity perception were used as reference. Considering the variable "diet perception", the five levels were computed into three levels: "not healthy" which include "Very not healthy" and "unhealthy"; "Neither unhealthy nor healthy" and "healthy" which includes "healthy" and "really healthy". For this variable, the modality "healthy" was used as reference. Values and associations with p-value $<5 \%$ were considered significant and $95 \% \mathrm{CI}$ was considered for adjusted OR values.

\section{Results}

\subsection{Sample description}

A total of 395 adolescent girls aged $15-19$ years old participated in this study with $57.7 \%$ attending public school and $42.3 \%$ in private schools. The average age of participants was $16.7 \pm 1.26$ years. More than two-thirds of the participants $(69.3 \%)$ were younger adolescents aged 15-17 years old. The age difference between public and private schools is significant $(p<0.001)$. In the sample, the girls in public schools were older $(17.06 \pm 1.22)$ than those in private schools $(16.35 \pm 1.20)$ $(\mathrm{p}<0.001)$.

\subsection{Self-perception}

In both age groups (15 - 17 and 18 - 19 years old), suffering from iron-deficiency anaemia has been perceived by $18.23 \%$ of the school adolescent girls while $55.69 \%$ thought there is a probability for them to be anaemic and $26.08 \%$ perceived they are not (Table 1 ). In $15-17$ years adolescents, respectively $18.2 \%, 61.2 \%$ and $20.7 \%$ perceived themselves as anaemic, probably anaemic and not anaemic. Similarly, in the age group of $18-19$ years, $18.2 \%, 53.3 \%$ and $28.3 \%$ of the girls perceived themselves as anaemic, probably and not anaemic. There is no significant difference between age groups regarding anaemia self-perception.

More than two-thirds of those attending public schools (68.4\%) reported to probably suffer from IDA while respectively $19.7 \%$ and $11.8 \%$ of them reported the perception of not being anaemic and being anaemic. In private schools, $34.7 \%$ reported not being anaemic, $38.3 \%$ perceived themselves as suffering from IDA and $26.9 \%$ perceived themselves as anaemic. There is no significant difference in schools and age groups regarding anaemia self-perception.

As one of the issues in adolescent health, being overweight/obese was perceived by $9.87 \%$. Two-thirds of them $(66.58 \%)$ thought they may be overweight/obese and $23.55 \%$ were convinced they are not overweight/obese. In each age group, the proportion of adolescents who reported being overweight/obese was $10.6 \%$ among younger adolescents and $8.3 \%$ among the older. Likewise, $0.4 \%$ in public and $22.8 \%$ in private schools also noticed this perceived health status with a significant difference between private and public schools $(\mathrm{p}<0.001)$.

Overall, $18.73 \%$ of participants reported their eating habits to be unhealthy with $9.62 \%$ perceiving their diet as 
very unhealthy and $9.11 \%$ as unhealthy. On the other hand, more than half of adolescent girls (57.72\%) perceived their usual dietary patterns as healthy. Among those who perceived their diet as healthy, $43.32 \%$ reported the diet as healthy and $14.4 \%$ as very healthy (Table 1). In addition, $23.54 \%$ of participants characterized their diet as neither unhealthy nor healthy. Considering school status, $45.2 \%$ and $40.7 \%$ of adolescents perceived their diet as healthy in public and private schools respectively while $17.5 \%$ and $10.2 \%$ reported their diet to be much healthier in public and private schools respectively. Adolescents in public schools perceived their diet healthier than those from private schools $(\mathrm{p}<0.001)$.

Table 1. Self-perception of school adolescent girls' overweight/obesity status, anaemia and dietary practices in urban Benin $(\mathrm{N}=395)$

* Chi2 test ; ** Wilcoxon - Mann Whitney tests

\begin{tabular}{|c|c|c|c|c|}
\hline \multirow{3}{*}{$\begin{array}{l} \\
\begin{array}{l}\text { Self-perception } \\
\text { of anemia ( } p \text { - } \\
\text { value) }\end{array} \\
\end{array}$} & \multicolumn{2}{|c|}{ School Type } & \multicolumn{2}{|c|}{ Age group } \\
\hline & $\begin{array}{l}\text { Public } \\
\text { n (\%) }\end{array}$ & $\begin{array}{r}\text { Private } \\
\text { n (\%) }\end{array}$ & $\begin{array}{c}15-17 y \\
\text { n (\%) }\end{array}$ & $\begin{array}{c}18-19 y \\
n(\%)\end{array}$ \\
\hline & \multicolumn{2}{|c|}{$<0.001^{*}$} & \multicolumn{2}{|c|}{$0.235^{*}$} \\
\hline Not anaemic & $\begin{array}{c}45 \\
(19.7 \%)\end{array}$ & $\begin{array}{c}58 \\
(34.7 \%)\end{array}$ & $\begin{array}{c}78 \\
(28.5 \%)\end{array}$ & $\begin{array}{c}25 \\
(20.7 \%)\end{array}$ \\
\hline May be anaemic & $\begin{array}{c}156 \\
(68.4 \%)\end{array}$ & $\begin{array}{c}64 \\
(38.3 \%)\end{array}$ & $\begin{array}{c}146 \\
(53.3 \%)\end{array}$ & $\begin{array}{c}74 \\
(61.2 \%)\end{array}$ \\
\hline Anaemic & $\begin{array}{c}27 \\
(11.8 \%) \\
\end{array}$ & $\begin{array}{c}45 \\
(26.9 \%)\end{array}$ & $\begin{array}{c}50 \\
(18.2 \%) \\
\end{array}$ & $\begin{array}{c}22 \\
(18.2 \%)\end{array}$ \\
\hline $\begin{array}{l}\text { Self-perception } \\
\text { of dietary } \\
\text { practices ( } p \text { - } \\
\text { value) }\end{array}$ & \multicolumn{2}{|c|}{$<0.001 *$} & \multicolumn{2}{|c|}{$0.072 *$} \\
\hline Really Unhealthy & $\begin{array}{c}25 \\
(11 \%)\end{array}$ & $\begin{array}{c}13 \\
(7.8 \%)\end{array}$ & $\begin{array}{c}26 \\
(9.5 \%)\end{array}$ & $\begin{array}{c}12 \\
(9.9 \%)\end{array}$ \\
\hline Unhealthy & $\begin{array}{c}19 \\
(8.3 \%)\end{array}$ & $\begin{array}{c}17 \\
(10.2 \%)\end{array}$ & $\begin{array}{c}25 \\
(9.1 \%)\end{array}$ & $\begin{array}{c}11 \\
(9.1 \%)\end{array}$ \\
\hline $\begin{array}{l}\text { Neither unhealthy } \\
\text { nor healthy }\end{array}$ & $\begin{array}{c}41 \\
(18 \%)\end{array}$ & $\begin{array}{c}52 \\
(31.1 \%)\end{array}$ & $\begin{array}{c}75 \\
(27.4 \%)\end{array}$ & $\begin{array}{c}18 \\
(14.9 \%)\end{array}$ \\
\hline Healthy & $\begin{array}{c}103 \\
(45.2 \%) \\
\end{array}$ & $\begin{array}{c}68 \\
(40.7 \%) \\
\end{array}$ & \begin{tabular}{|c|}
116 \\
$(42.3 \%)$ \\
\end{tabular} & $\begin{array}{c}55 \\
(45.5 \%) \\
\end{array}$ \\
\hline Very healthy & $\begin{array}{c}40 \\
(17.5 \%) \\
\end{array}$ & $\begin{array}{c}17 \\
(10.2 \%) \\
\end{array}$ & \begin{tabular}{|c|}
32 \\
$(11.7 \%)$ \\
\end{tabular} & \begin{tabular}{|l}
25 \\
$(20.7 \%)$ \\
\end{tabular} \\
\hline $\begin{array}{l}\text { Self-perception of } \\
\text { overweight/obese } \\
\text { (p-value) }\end{array}$ & \multicolumn{2}{|c|}{$<0.001 * *$} & \multicolumn{2}{|c|}{$0.517 * *$} \\
\hline $\begin{array}{l}\text { Not } \\
\text { overweight/obese }\end{array}$ & $\begin{array}{c}82 \\
(36 \%)\end{array}$ & $\begin{array}{c}11 \\
(6.6 \%)\end{array}$ & $\begin{array}{c}63 \\
(23 \%)\end{array}$ & $\begin{array}{c}30 \\
(24.8 \%)\end{array}$ \\
\hline $\begin{array}{l}\text { Maybe } \\
\text { overweight/obese }\end{array}$ & $\begin{array}{c}145 \\
(63.6 \%)\end{array}$ & $\begin{array}{c}118 \\
(70.7 \%)\end{array}$ & $\begin{array}{c}182 \\
(66.4 \%) \\
\end{array}$ & $\begin{array}{c}81 \\
(66.9 \%)\end{array}$ \\
\hline Overweight/obese & $\begin{array}{c}1 \\
(0.4 \%)\end{array}$ & $\begin{array}{c}38 \\
(22.8 \%)\end{array}$ & $\begin{array}{c}29 \\
(10.6 \%)\end{array}$ & $\begin{array}{c}10 \\
(8.3 \%)\end{array}$ \\
\hline
\end{tabular}

\subsection{Self-perception of IDA, overweight/obesity} influence on eating habits

Table 2 shows the association of adolescent girls' selfperception of IDA and current eating habits as well as their self-perception of overweight/obesity and their current eating habits.

Self-perception as "not anaemic" is negatively associated with daily consumption of dark green leafy vegetable and vitamin C-rich fruits ( $\mathrm{OR}=0.389$ [95\%CI $0.183-0.825]$ ) and self-perception as being "maybe overweight/obese" is positively associated with meat products consumption $(\mathrm{OR}=3.891$ [95\% CI 1.49510.124]). Indeed, the more the adolescents perceived themselves as not suffering from anaemia, the less likely they are to increase their daily consumption of dark green leafy vegetable and vitamin $\mathrm{C}$-rich fruits.

Table 2. Association between adolescent girls' selfperception of IDA, overweight/obesity and eating habits.

*p < 0.05; CI: confidence interval; GDR: Global Dietary Recommendations; a: reference is "“maybe anaemic", model adjusted"; b: reference is "overweight/obesity"; c: reference is "healthy"

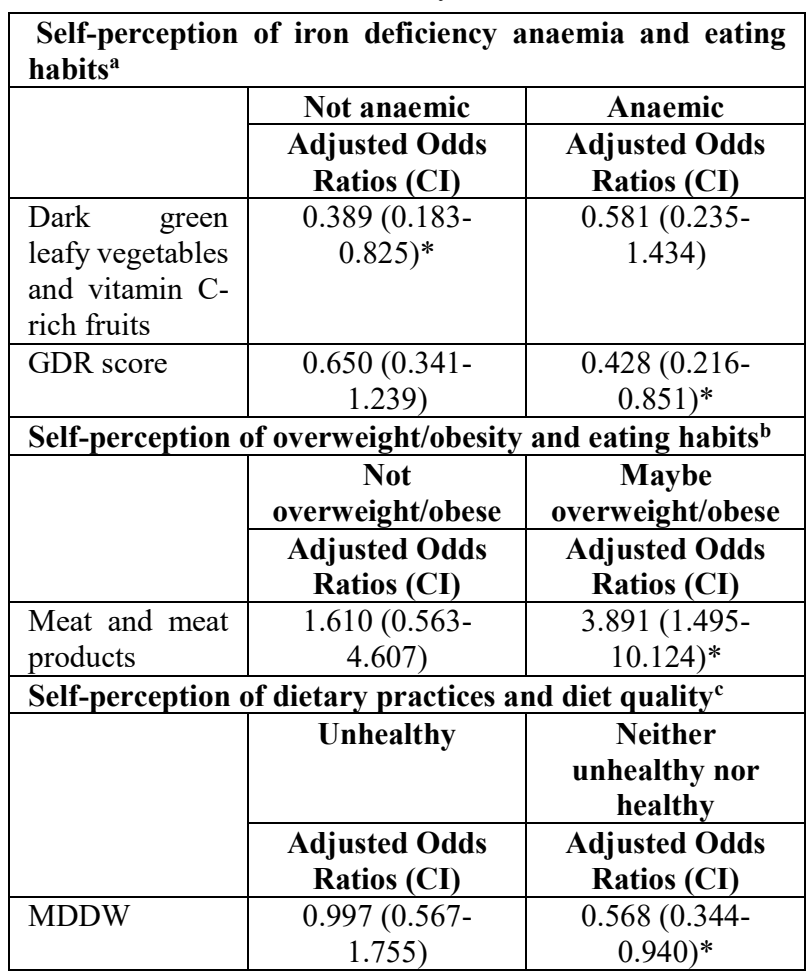

Consumption of unhealthy foods was not related to perception of overweight/obesity status (not in table 2). Likewise, a negative association was found between the perceived anaemia and GDR and participants who perceived themselves anaemic have less chance to reach the GDR than those who were unsure about being anaemic or not $(\mathrm{OR}=0.428$ [95\%CI 0.216-0.851]).

Adolescent girls who perceived their diet as "Neither unhealthy nor healthy" have lesser chance to reach the MDDW as compared to those who qualified their diet as healthy $(\mathrm{OR}=0.568$ [95\%CI 0.344-0.940]) (Table 2). There was no association between self-perception of dietary practices and GDR score.

\section{Discussion}

The present study assessed the self-perception by secondary school adolescent girls in the urban area of their iron deficiency anaemia status, diet quality and overweight/obesity status. Our study found that $26.08 \%$ of adolescent girls thought they are not anaemic while a share of $18.23 \%$ were seeing themselves as anaemic; selfperceived overweight/obesity were reported by $9.87 \%$ of adolescent girls and $23.55 \%$ were convinced not to be overweight nor obese; $57.72 \%$ of them perceived their current diet as healthy and very healthy while $18.73 \%$ deemed their diet as unhealthy and very unhealthy. 
Findings also showed that the more adolescents perceived themselves as not exposed to anaemia, the less likely they are to increase their daily consumption of dark green leafy vegetable and vitamin C-rich fruits $(\mathrm{OR}=$ 0.389 [ $95 \%$ CI $0.183-0.825]$ ). On the other hand, the selfperception of overweight/obesity status was positively associated with the meat and meat product consumption among the school adolescent girls (OR $=3.891$ [95\% CI $1.495-10.124]$ ). Finally, girls who perceived their diet as "Neither unhealthy nor healthy" have a lesser chance to reach the MDDW as compared to those who qualified their diet as healthy (OR $=0.568$ [95\%CI 0.344-0.940]).

Concerning self-perceived IDA status, a previous study showed that the proportion of adolescent girls who saw themselves as anaemic was low compared to those who thought they are not [23]. Our findings indicated similar trends, as well as our results about self-perception of dietary practices appearing similar to previous studies reporting that more than half of participants perceived their diet as healthy and very healthy [24-26]. This perception of personal diet as healthy in most urban adolescent girls in Benin in the current study might be an obstacle to improving diet quality, as they might not see the need to improve their diet quality. Among those who reported self-perceived healthy diet, the majority were attending public schools compared to those from private schools in the current study. This is different from previous findings reporting that more adolescents in private schools reported a good quality diet than their peers from public schools in Brazil [26]. The possible reasons for these discrepancies might first be the higher sample size in this study compared to our study. Moreover, the focus on only adolescent girls in our study compared to the study on Brazilian adolescents which show that more boys perceived their diet as healthy than girls, can also explain this difference in the two studies results, assuming that more boys perceived their diet as healthy in private schools than public schools. We also consider the geographic, environmental and socio-cultural differences between Benin and Brazil making adolescents in private schools in urban Benin more exposed to unhealthy diets. This finding indicates the need to reinforce health promotion and nutrition education activities, especially in secondary school adolescents to reduce the consumption of unhealthy foods.

Regarding the self-perception of IDA influence on eating habits, our results showed that the more adolescents perceived themselves as not exposed to anaemia, the less likely they are to increase their daily consumption of dark green leafy vegetable and vitamin C-rich fruits. Also, we had indication that those who perceived themselves as anaemic have lesser chance to reach the GDR than those who were unsure about being anaemic or not. Though only perception toward IDA is considered in our study, previous studies findings on knowledge, attitude and practices of women and their IDA status could be at play in our results. Therefore, only half of women at reproductive age have positive knowledge, attitude and practice towards iron deficiency anaemia including consumption of iron-rich foods [23, 27]. Then, the decrease of daily consumption of iron-rich foods resulting from self-preception of being or not anaemic, in our study exposed adolescent girls to anaemia. It seems important to reinforce the knowledge, attitude and practice in adolescent girls to increase their self-perception and confidence about not being anaemic as results of increasing attitudes towardsreducing iron deficiency anaemia. Moreover, a correlation was found between diet quality and haemoglobin levels as an IDA indicator in another study [28], and another one found that dietary quality was found to be higher in subjects without anaemia [29]. Since high diet quality is related to the consumption of healthier foods including iron-rich foods, it is unsurprising in this study that subjects who present a poor quality of diet, self-perceived themselves as anaemic.

With regards to self-perception of overweight/obesity, our findings are supported by a study in Spanish adolescents showing that more than half of them considered themselves as normal weight and low proportion as overweight and obese [30]. A study in Morocco also confirmed this low proportion of adolescents who consider themselves overweight [31]. These outcomes might be justified by overweight/obesity misperceptions in adolescents as described in previous studies $[32,33]$. In details, more adolescents in private schools $(22.8 \%)$ perceived themselves as overweight or obese compared to those from public schools $(0.4 \%)$. This can probably be explained by the high economic status of adolescents attending private schools compared to those from public schools and then their exposition to junk and unhealthy foods in their environment as drivers to overweight and obesity.

Furthermore, in this study, self-perceived overweight/obesity was not associated with unhealthy foods consumption. Previous findings were also the same [34-37]. This can be the results of the limited knowledge of adolescent girls of the different unhealthy foods, making them unaware of the health consequences of these foods intake. Insight is needed into the knowledge of unhealthy foods in this study population with nutrition education intervention.

On the other hand, the self-perception of overweight/obesity status was positively associated with meat products consumption among school adolescent girls and those who were unsure if they are overweight/obese or not are more likely to consume meat and meat products than those who declared themselves as overweight/obese. We assumed that adolescent girls who perceived themselves overweight/obese are less into meat and meat products intake because they see meat and meat products as fattening foods that can enhance their perceived health status.

Likewise, it was reported that adolescents who consume more meat per week are less obese than those who consumed less than one serving per week [38]. The percentage of overweight and obesity was also found higher among adolescents with no meat intake [39]. However, an ecological analysis pointed out that populations with the highest availability levels of meat (meat protein) have the highest prevalence of overweight and obesity [40]. The dissimilarities are observed because animal protein-rich diets are into weight reduction especially when the protein intake cover $10-15$ percent 
of calorie intake [41], but can be damaging for maintaining weight through adult life when the dietary protein is above these recommendations [42]. Thus, it seemed that meat intake is related to overweight and obesity, and it is important to adjust the perception about meat intake towards obesity and avoid restricting meat intake to prevent overweight and obesity among adolescent girls.

Compared with previous studies, a self-perceived healthy diet was related to MDDW as diet quality but not with the GDR score. Adolescent girls who considered their diet as healthy were likely to reach the MDDW than those who were unsure about their diet quality. The limited research assessing the association between the self-perception of diet quality by adolescents and its association with healthy eating reported comparable results $[26,43]$. It should be emphasized that adolescent girls do not perceive their diet quality based on the GDR because of their limited knowledge of the dietary recommendations. Therefore, it is understandable that they only associated the perception of their current diet with the MDDW because they assumed that the consumption of the diverse food groups can be sufficiently defined as healthy. This finding indicates the need to reinforce adolescents' knowledge of healthy diet in other to improve their dietary quality.

A major limitation of our research is the restriction of the sample to only secondary school settings. This may unable to capture a larger spectrum of self-perception about overweight/obesity, IDA and diet quality. Also, this might explain the lack or weak strength of some association between self-perception and eating behaviour. Nonetheless, to our knowledge, there is a limited number of studies addressing the diet and health status of adolescents in low and midde-income countries (LMICs). Exploring the self-perception of anaemia and overweight in association to eating habits among adolescents in Benin, we raise the importance of understanding the perceptions of the targets prior to designing behaviour change interventions in nutrition. It has been shown that the best behavioural change interventions are those with participatory approaches [44]. Considering that individual's perception of risk to a threat is an important determinant of health behaviour [11], this study is worthy for effective intervention to enhance secondary schools' adolescent girls eating behaviours in urban area.

\section{Conclusion}

Our study found that most adolescent girls in urban, perceived themselves as healthy or maybe healthy and their diet as healthier. Most alarming, their self-perception is in a different way related to their dietary habits and does not, in general, facilitate the improvement of their diet quality. Results of this study indicatedthat an accurate perception of health status and diet quality is essential to the success of health promotions intervention in adolescent. Even better, insight into the other influencing factors at both individual and environmental levels of eating habits are important. This will in a positive way simplify the designing of appropriate and effective multilevel interventions to lead to healthy behaviours among adolescent girls over the lifespan.

\section{References}

1. Z. Lassi, A. Moin, Z. Bhutta, Nutrition in Middle Childhood and Adolescence. In: Bundy DAP, Silva Nd, Horton S, et al., editors. Child and Adolescent Health and Development. 3rd edition. Washington (DC), Chapter 11 (2017)

2. E.C. Keats, A.I. Rappaport, S. Shah, C. Oh, R. Jain, Z.A. Bhutta, Nutrients, 10, 12 (2018).

3. INSAE et ICF, Enquête Démographique et de Santé au Bénin, 2017-2018. Cotonou, Bénin et Rockville, Maryland, USA (2019)

4. R. K. Benedict, A. Schmale, S. Namaste. Adolescent Nutrition 2000-2017: DHS Data on Adolescents Age 15 - 19, DHS Comparative Report No. 47. Rockville, Maryland, USA: ICF (2018)

5. T. Mbogori, K. Kimmel, M. Zhang, J. Kandiah, Y. Wang, AIMS Public Health, 7, 3 (2020).

6. R. Kapur, (2020). [Consulted 03 May 2021]: https://www.researchgate.net/publication/34252179 8 Role of Food and Nutrition in Promoting Hea 1th and Well-being

7. L. Elizondo-Montemayor, C. Hernández-Escobar, E. Lara-Torre, B. Nieblas, M. Gómez-Carmona. J Pediatr Adolesc Gynecol. 30, 2. (2017).

8. A. Papadaki, G. Hondros, A. Scott, M. Kapsokefalou, Appetite 49, 1 (2007).

9. A.W. El, S. Suominen, A. Samara, Cent Eur J Public Health 23, 4 (2015).

10. H. Osei-Kwasi, A. Mohindra, A. Booth, A. Laar, M. Wanjohi, F. Graham, R. Pradeilles, E. Cohen, M. Holdsworth, Public Health Nutr. 23, 14 (2020).

11. Ferrer \& W.M. Klein. Curr Opin in Psychol., 5 (2015).

12. T.M. Powell-Wiley, P. E. Miller, P. Agyemang, T. Agurs-Collins, J. Reedy, Public Health Nutr. 17, 12 (2014)

13. C. Gregory, T. Smith, M. Wendt, Econ Inf Bull. 83 (2011)

14. V. Kriaucioniene, A. Raskiliene, D. Petrauskas, J. Petkeviciene. Nutr. 13, 1599 (2021)

15. A. Haynes, I. Kersbergen, A. Sutin, M. Daly, E. Robinson. Obes Rev. 19, 3 (2018).

16. R.B. Awuah, E.K. Colecraft, M.L. Wilson, L.K. Adjorlolo, N.J Lambrecht, H. Nyantakyi-Frimpong, A.D. Jones, Matern Child Nutr. e13181 (2021).

17. J. B. Gaylis, S.S. Levy, M. Y. Hong, Int J Adolesc Youth, 25, 1 (2019).

18. FAO. Guidelines for assessing nutrition-related Knowledge, Attitudes and Practices, by Yvette Fautsch Macías. Rome. (2014)

19. FAO. Dietary Assessment: A resource guide to method selection and application in low resource settings. Rome. (2018)

20. K. da Silva Lopes, Y. Takemoto, M.N. Garcia-Casal, E. Ota, Cochrane Database Syst Rev 2018, 8 (2018). DOI: 10.1002/14651858.CD013092.

21. FAO. Minimum dietary diversity for women. Rome. (2021).

22. W. Herforth, D. Wiesmann, E. Martínez-Steele, G. Andrade, C. A. Monteiro. Curr Dev Nut 4, 12 (2020). https://doi.org/10.1093/cdn/nzaa168 
23. N. N. Abu-Baker, A. M. Eyadat, A. M. Khamaiseh. Heliyon 7, 2 (2021)

24. C. Batis, A. Castellanos-Gutiérrez, T.C. Aburto, A. Jiménez-Aguilar, J.A. Rivera, I. Ramírez-Silva, Nutr J 19, 59 (2020).

25. C.M. Gago, A. Lopez-Cepero, J. O'Neill, M. Tamez, K. Tucker, J.F.R. Orengo, J. Mattei, Front Nutr 8 (2021)

26. P.R.M. Rodrigues, R.M.V. Gonçalves-Silva, M.G. Ferreira, R.A. Pereira. Ciênc. saúde colet 22, 5 (2017).

27. A. Rama, C Anuradha. Int J Clin Obstet Gynaecol 4, $3(2020)$

28. M. Merita, A. Wulansari, M. T. Sari, K. Kasyani and S. Fitrianti, Pak J Nutr 18 (2019)

29. A. Rina, K. Nadiya, E.A. Andini, A.A. Setianingsih, A.A. Sadariskar, E. Prafiantini, F. Wirawan, E. Karyadi, M.K. Raut, PLoS ONE 15, 4 (2020).

30. I. Jáuregui-Lobera, A. Iglesias Conde, J. Sánchez Rodríguez, J. Arispon Cid, C. A. Ramírez, G. Herrero Martín, P. Bolaños-Ríos, Nutr Hosp 35, 5 (2018).

31. K. Boutahar, A. Chetoui, K. Kaoutar, M. Najimi, F. Chigr, Rev Epidemiol Sante 67, 5 (2019)

32. M. Fan, Y. Jin, J. Khubchandani, J Pediatr Nurs 29, 6 (2014).

33. K.R. Sonneville, I.B. Thurston, C.E. Milliren, H.C. Gooding, T.K. Richmond, Int J Eat Disord 49, 10 (2016)

34. J. Fredrickson, P. Kremer, B. Swinburn, A. de Silva, M. McCabe, J Health Psychol 20, 6 (2015).

35. K.A. Patte, R.E. Laxer, W. Qian, S.T. Leatherdale, Soc Sci Med Popul Health 2: 841-849 (2016)

36. L. Cai, T. Zhang, J. Ma, L. Ma, J. Jing, Y. Chen, J Epidemiol 27, 7: 338-345 (2017).

37. M. Fan, Y. Jin, Int J Environ Res Public Health 12, $11(2015)$

38. G.H. Kim, S.W. Shin, J. Lee, J. H. Hwang, S.W. Park, J.S. Moon, H.J. Kim, H.S. Ahn, Nutr. J. 16, 31 (2017)

39. S.M. Shin, J Obes Metab Syndr. 26, 3 (2017)

40. W. You, M. Henneberg, BMC Nutrition 2, 1 (2016)

41. WHO. Diet, Nutrition and the Prevention of Chronic Diseases. Report of a Joint WHO/FAO Expert Consultation. In: Technical Report Series No. 916. Geneva (2003)

42. I. Elmadfa. European nutrition and health report. Basel, London: Karger (2009)

43. C. E. Velazquez, K. E. Pasch, N. Ranjit, G. Mirchandani, D. M. Hoelscher, J. Acad. Nutr. Diet. 111, 11 (2011).

44. E.L.K. Bartholomew, C.M. Markham, R.A.C. Ruiter, M.E. Fernandez, G. Kok, G.S. Parcel, Planning health promotion programs: An Intervention Mapping approach (4th ed.) Hoboken, NJ: Wiley (2016) 